\title{
Influence of Septoria glycines Hemmi on the enzymes' activity of hydrolytic Glycines max (L.) Merr seed complex
}

\author{
Natalia Martynenko*, Svetlana Lavrentieva, and Olga Tarasova \\ Federal State Budget Scientific Institution Federal Research Center "All-Russian Scientific Research \\ Institute of Soybean", Ignatevsky highway, 19, 675027 Blagoveshchensk, Russia
}

\begin{abstract}
The Septoria leaf spot (Septoria glycines Hemmi), is a harmful pathogen of soybean. To create a resistant variety to this pathogen, a detailed study of physiological processes at the biochemical level is necessary. Enzymes play a leading role in adapting to stressors. It was shown that the specific activity of esterases and RNases of soybean seeds infected with septoria decreased, relative to the control. Multiple forms of enzymes with different electrophoretic mobility were identified, which indicates a decrease in metabolism under the influence of fungal disease. At the same time, the specific activity of amylases and acid phosphatases of soybean seeds was not strongly affected by S. glycine, as evidenced by the relatively stable multiple forms of enzymes.
\end{abstract}

\section{Introduction}

The phytopathological state of fields is of great importance among environmental factors affecting crops since fungal diseases are one of the main causes of crop loss. Soybean septoria blight Septoria glycines Hemmi (S. glycines) (brown soybean spotting) occurs in the Russian Federation only in the Far East [1] and affects cotyledons, leaves, fruits (beans) and seeds. Through spots are formed on cotyledons under the pathogen influence; they are limited by roller-shaped calluses. Infected cotyledons get dry and die. Ternate leaves are covered with small rusty-brown angulated spots of up to $0.4 \mathrm{~cm}$, which gradually blacken. The formed spots are limited by leaves' veins. The infection goes from the bottom up and therefore first manifests itself on the lower leaves. Under the epidermis in spot locations small pycnidia of black color are developed, which leads to a yield decrease, deterioration of technical and sowing qualities of soybean seeds [2-4]. Pathogens' ability to penetrate and reproduce in plant tissues is determined by the activity of their hydrolytic enzymes. Interest in these enzymes is due to a number of reasons, one of which is the occurrence and development of the pathological process in plant tissues [5]. According to literary data, ribonuclease (RNAase) (E.C. 3.1) and acidic phosphatase (E.C. 3.1.3.2) are enzymes with broad substrate specificity [6]. In most plant viruses, their genetic material is represented by RNA, thus it can be assumed that extracellular RNAase caused

\footnotetext{
* Corresponding author: mvn@vniisoi.ru
} 
by cultivation is one of the components of antiviral protection on early stages of infection [7]. Phosphatases are enzymes involved in the hydrolysis of phosphoric acid esters and are also widely distributed in all living cells. Enzymes of the esterase complex (3.1.1) are involved in the hydrolysis of complex ester bonds, including lipids. The main amylolytic enzymes that make up the amylase complex include: $\alpha$-amylase, $\beta$-amylase (E.C. 3.2.1.1 and 3.2.1.2), glucoamylase, oligo-1,6-glucosidase involved in starch conversion, resulting in the formation of products such as glucose, maltose and maltotriose [8,9]. An effective mechanism to prevent the penetration of phytopathogens into the plant and their reproduction is the suppression of hydrolase activity by specific protein inhibitors [10,11]. These inhibitors deactivate foreign enzymes of invading microorganisms and increase plant resistance by reducing the degradation intensity by their own enzymes [12]. Since morphogenetic partners properties determine the development of plant resistance to pathogens, it is necessary to study the role of hydrolytic enzymes and their inhibitors in the formation of relationships between plant, host and pathogen considering the organism's characteristics. Therefore, the study of biochemical properties of an infected plant is an important step in understanding the nature of resistance to pathogens.

The aim of the research was to study Septoria glycines Hemmi influence on specific activity and multiple forms of amylases, esterases, RNAases and acidic phosphatases of soya bean seeds of various maturity groups to identify protein markers under biotic stress conditions.

\section{Materials and methods}

The object of the study was septoriosis-infected and uninfected seeds of 'FSC ARSI of Soybean' breeding soybean varieties: Kruzhevnitsa, Sentiabrinka, Umka, Vereteyka (earlyripening); Dauria, Zolushka, Lazurnaya (mid-ripening) and Topaz (ultra-early ripening).

The selection of seeds infected with $S$. glycines was performed in laboratory conditions by visual examination of seeds: the presence of round red-brown spots on $6 \ldots 10 \mathrm{~mm}$ diameter cotyledons with numerous pycnidia. Uninfected seeds were determined by cleanliness, germination, evenness, without signs of disease and presence of weeds. To detect plant response to stress caused by fungal infection Septoria glycines Hemmi, protein extracts were prepated from soy seeds $(500 \mathrm{mg})$ to: determine the protein amount by Lowry method, determine specific activity of enzymes (RNAase, acidic phosphatases, esterase and amylase complexes) and concentrations of malondialdehyde (MDA); all analyses were carried out by spectrophotometric method on the spectrophotometer (Cary50 13620-08, Australia) in two biological and three analytical repetitions. Multiple forms of enzymes were detected by the method of plate electrophoresis in 8 and $10 \%$ polyacrylamide gel on the Bio-Rad device (USA). The identification of enzyme forms was carried out by appropriate histochemical methods. To characterize multiple forms of enzymes, their relative electrophoretic mobility (Rf) was used, where the numbering of the enzymes forms studied was given in ascending order - from high mobility to low mobility forms. Each enzymes form was assigned with its abbreviated designation according to the values of their $\operatorname{Rf}[14-17]$.

The resulting experimental data was processed using the Statistica 10 software, graphical data representation - Excel (2010). The results were expressed as mean $(n=6) \pm$ standard deviation, differences were considered statistically significant at $p<0,05$. 


\section{Results and discussion}

There are numerous experimental data on the participation of active oxygen forms in the induction of the plants' protective response, but sources and ways of generating these compounds in pathogenesis remain not so studied [18]. One of the indicators of the plants' oxidative stress intensity is the change in the MDA level - a product of lipid peroxidation [19]. The MDA content can be the judgment basis on the plant cell membranes' damage degree because of oxidative stress [20].

During our research, it was found that when soybean seeds of different maturity groups were infected by $S$. glycines, MDA content increased in comparison with control (Fig. 1). It should be noted that the greatest increase in MDA concentration occurred in the earlyripening soybean varieties: Kruzhevnitsa, Umka - 2 times, Vereteyka $-4,5$ times and midripening Lazurnaya variety -2 times relative to control. In the mid-ripening variety Dauria and the ultra-early ripening variety Topaz, the MDA level in infected seeds remained at the level of control, which indicates the stability of these varieties in conditions of infection.

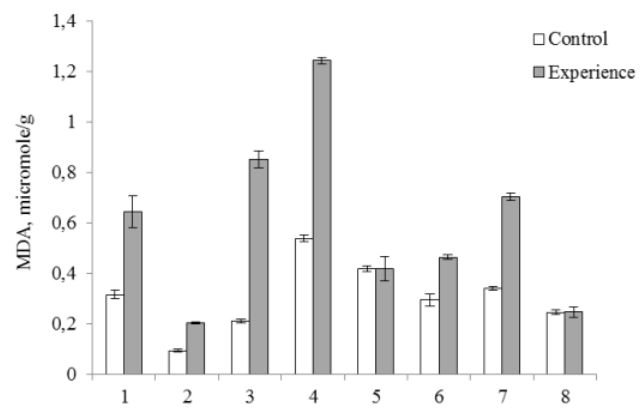

Fig. 1. Concentration of MDA ( $\mu \mathrm{mol} / \mathrm{g}$ ) of soybean varieties seeds in conditions of septoriosis infection: 1 - Kruzhevnitsa, 2 - Sentiabrinka, 3 - Vereteyka, 4 - Umka, 5 - Dauria, 6 -Zolushka, 7 - Lazurnaya, 8 - Topaz

The research results of specific hydrolases activities showed a decrease in specific activities of RNAases, acid phosphatases, esterases and amylases of soybean seeds. At the same time, in the early-ripening soybean varieties specific activity of amylases increased relative to control, which is probably due to an alteration in carbohydrate-phosphate and lipid metabolism under the influence of $S$. glycines (Fig. 2A, 3A, 4A, 5A).

Analyzing the specific RNAase activity in conditions of fungal disease infection, its decrease in soybean seeds relative to control was established. The greatest decrease in soybean RNAases specific activity was revealed in Sentiabrinka early ripening variety and Lazurnaya mid-ripening variety compared to control by 11 and 15 times respectively (Fig. 2A). In most plant viruses, genetic material is represented by RNA; based on this, it can be said that extracellular RNAases induced by damage are one of antiviral protection components. Sangayev et al. showed that tobacco plants with increased extracellular RNAase activity are characterized by increased resistance to tobacco mosaic virus [21]. This supports the hypothesis about the involvement of plants' extracellular RNAase in the formation of resistance to viruses. 
A

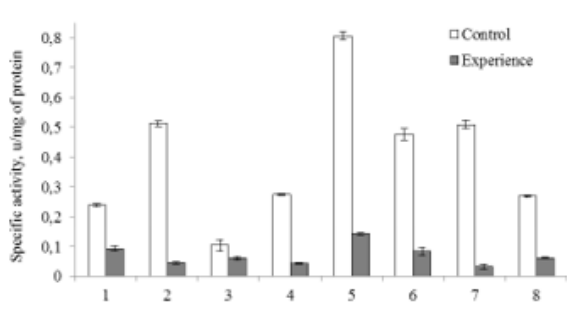

B

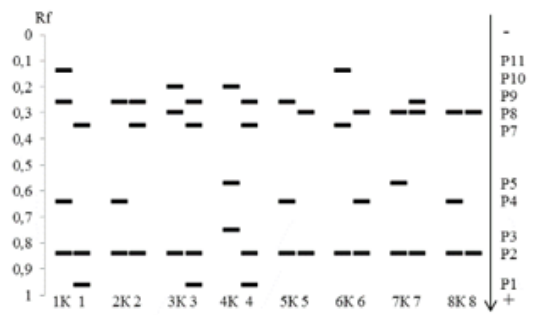

Fig. 2. Specific activity (A) and zymograms scheme (B) of RNAase seeds of soybean varieties in conditions of septoriosis infection: $\mathrm{C}$ - Control; 1 - Kruzhevnitsa, 2 - Sentiabrinka, 3 - Vereteyka, 4 - Umka, 5 - Dauria, 6 - Zolushka, 7 - Lazurnaya, 8 - Topaz.

$\rightarrow-$ electrophoresis direction from cathode to anode

During the electrophoretic spectra study of soybean varieties' seeds RNAase of different maturity groups, 10 enzyme forms were found. At that time, in soybean varieties affected by fungal disease, one stable form of $\mathrm{P} 2(\mathrm{Rf}=0,82)$ was distinguished and there were no forms with average electrophoretic mobility. In uninfected soybean seeds $S$. glycines forms with high, medium and low electrophoretic mobility have been identified. This may be a consequence of the oxidative stress effect caused by the biotic factor influence (Figure 2B).

As a result of the specific esterases activity analysis, its decrease in relation to control was revealed, and it was shown that the early-ripening Sentiabrinka variety showed a 4 times decrease, the mid-ripening Lazurnaya variety and ultra-early ripening Topaz variety 3 times, the early-ripening Vereteyka variety and the mid-ripening Dauria -2 times relative to control (Fig. 3a). Perhaps it was caused by increased metabolism at the choline esters' hydrolysis, as well as the ability to react with organophosphorus compounds [22].

A

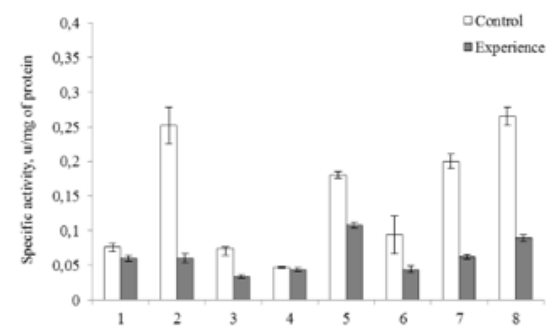

B

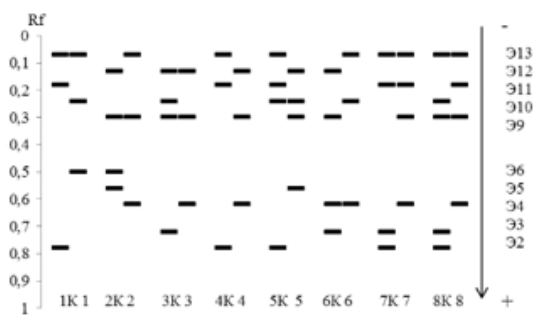

Fig. 3. Specific activity (A) and zymograms scheme (B) of soybean varieties seeds' esterases in septoriosis infection conditions: $\mathrm{C}$ - control, 1 - Kruzhevnitsa, 2 - Sentiabrinka, 3 - Vereteyka, 4 - Umka, 5 - Dauria, 6 - Zolushka, 7 - Lazurnaya, 8 - Topaz. $\rightarrow-$ electrophoresis direction from cathode to anode

Analysis of esterases' zymograms schemes of infected and uninfected soybean seeds $S$. glycines allowed to identify 10 forms of the enzyme. In the seeds of soybean varieties infected with fungal disease, forms with low electrophoretic mobility were completely absent, while in the conditions of infection 2 adaptive forms of soybean esterases were noted: $\mathrm{E} 9(\mathrm{Rf}=0,3)$ and $\mathrm{E} 4(\mathrm{Rf}=0,62)$ in seeds of soybean varieties Sentiabrinka, Vereteyka and Umka (early-ripening), E13 $(\mathrm{Rf}=0,07)$ and $\mathrm{E} 4(\mathrm{Rf}=0,62)$ in varieties Zolushka, Lazurnaya (mid-ripening) and Topaz (ultra-early ripening) (Figure 3B). S. glycines impact on soybean seeds led not only to a decrease in the specific esterase activity, but also to a 
decrease in the number of multiple enzymes forms due to the lack of forms with low electrophoretic mobility.

Phosphatases are enzymes involved in the hydrolysis of phosphoric acid esters and are common in all living cells. According to literary data, acid phosphatase can neutralize the action of a wide range of infections caused by various microorganisms [23].

A

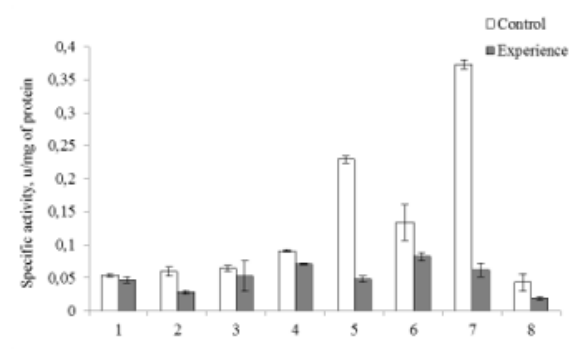

B

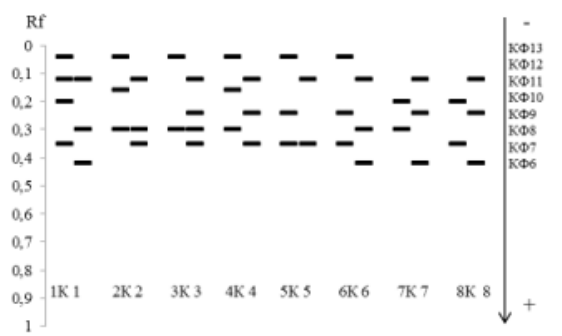

Fig. 4. Specific activity (A) and zymograms scheme (B) of acid phosphatases of soybean varieties' seeds in septoriosis infection conditions: C - Control, 1 - Kruzhevnitsa, 2 - Sentiabrinka,

3 - Vereteyka, 4 -- Umka, 5 - Dauria, 6 - Zolushka, 7 - Lazurnaya, 8 - Topaz. $\rightarrow-$ electrophoresis direction from cathode to anode

During the analysis of acid phosphatases' specific activity of soybean varieties seeds in conditions ofS. glycines infection, its slight decrease relative to control was established; however, mid-ripening soybean varieties Dauria (5 times) and Lazurnaya (6 times) showed the largest decrease (Figure 4A). Change in specific activity of acid phosphatase is associated with an alteration of carbohydrate-phosphorus and lipid metabolisms occuring under the influence of fungal infection [24]. The involvement of acid phosphatases in signal transduction and metabolism regulation by dephosphorylation of proteins is also known [25].

The electrophoretic spectra analysis of acid phosphatases of soybean varieties seeds infected and uninfected by fungal disease allowed to fix 8 forms of the enzyme. In the soybean seeds infected with $S$. glycines $\mathrm{KF} 12$ form $(\mathrm{Rf}=0,12)$ was allocated. Acid phosphatases' zymograms schemes of soybean seeds of various ripeness groups infected and uninfected with septoriosis have not shown significant quantitative changes; components with low and medium electrophoretic mobility were preserved (Figure 4B).

As a result of the specific amylases activity analysis of different maturity groups' soybean varieties seeds in conditions of septoriosis infection, its increase in seeds of earlyripening varieties Umka (2 times), Kruzhevnitsa (2,5 times) and Vereteyka (3 times) was recorded (Fig. 5A). At the same time, in other studied soybean varieties, a slight decrease in the specific amylases activity relative to control was recorded, which is consistent with the results of Akhmatova et al. - plants' infection by pathogens and processing of signaling molecules leads to an increase in the activity level of proteinase inhibitors and a decrease in the activity of own amylases in plant tissues [26]. 
A

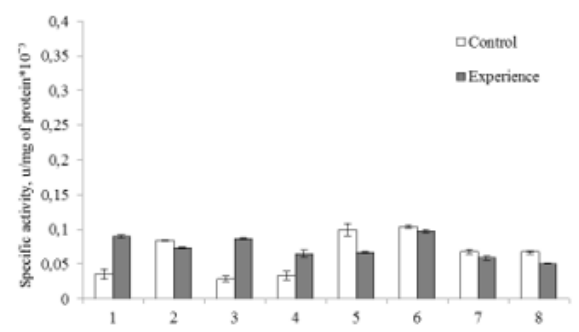

B

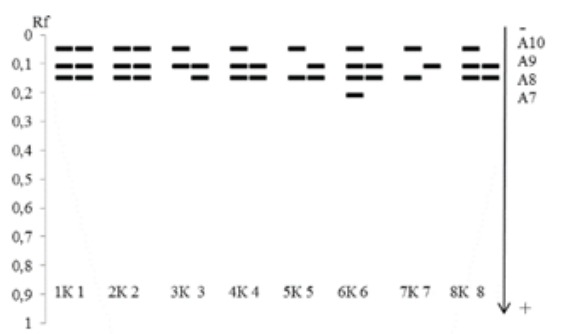

Fig. 5. Specific activity (A) and zymograms scheme (B) soybean varieties seeds amylases in septoriosis infection conditions: C - Control, 1 - Kruzhevnitsa, 2 - Sentiabrinka, 3 - Vereteyka, 4 - Umka, 5 - Dauria, 6 - Zolushka, 7 - Lazurnaya, 8 - Topaz. $\rightarrow-$ electrophoresis direction from cathode to anode

When analyzing the zymograms schemes of seeds amylase of soybean varieties infected and uninfected with fungal disease, a maximum 4 forms of the enzyme were established. In the soybean seeds infected with $S$. glycines, adaptive form A9 $(\mathrm{Rf}=0,11)$ and form A8 $(\mathrm{Rf}=0,15)$ were distinguished in all specimens except the mid-ripening Lazurnaya soybean variety. An adaptive form A10 $(\mathrm{Rf}=0,05)$ was found in soybean seeds uninfected with septoriosis, which is found in all samples. Electrophoretic amylases spectra of seeds infected and uninfected with fungal disease have not shown significant quantitative and qualitative changes, components with low electrophoretic mobility have been preserved (Figure 5B). Unchanged low electrophoretic mobility and the number of multiple forms in the affected and control samples indicates that the enzyme formation process is not disturbed.

\section{Conclusion}

It was established that in different maturity groups soybean seeds infected with $S$. glycines, specific activity of RNAases and esterases decreased. The results of the enzymogram schemes' study allowed to identify 10 multiple forms of esterases and RNAases of various electrophoretic mobility both in conditions of infection and in control samples, which indicates a decrease in metabolism under the influence of fungal disease. It was revealed that in soybean seeds the specific activity of amylases and acid phosphatases underwent minor influence by septoriosis, as evidenced by the relative stability of multiple forms of enzymes.

Thus, it was shown that RNAase and esterase have an increased polymorphism level, selective neutral behavior (in relation to the studied soybean varieties of different maturity groups), and allow to use them as protein markers to select the varieties most resistant to $S$. glycines at the molecular level.

\section{References}

1. L. A. Degas, Pests and diseases of soybeans in the Far East, 98 (2012)

2. V. A. Kuznetsova, A. A. Blinova, L. E. Ivachenko, Achievements of science and technology of agriculture, 34, 39 (2020)

3. V. A. Kuznetsova, A. A. Blinova, O. N. Tarasova, L. E. Ivachenko, Agrarian Bulletin of the Urals, 47 (2020) 
4. G.L. Hartman, C.R. Bowen, J.S. Haudenshield, T.R. Cary, B.W. Diers, Agronomy Journal, 107(6), 2373 (2015)

5. L.G. Yarullina, A.R. Ahatova, R.I. Kasimova, Applied Biochemistry and Microbiology, 53, 562 (2017)

6. J. Zheng, Y. Wang, Y. He, J. Zhou, Y. Li, Q. Liu, X. Xie, Plant Sci, 214, 99 (2014)

7. V.T. Sinegovskaya, O.A. Terekhova, S.I. Lavrentieva, L.E. Ivachenko, K.S. Golokhvastov, Russian agricultural science, 27 (2019)

8. N.V. Agafonova, N.V. Doronina, Yu.A. Trotsenko, Applied Biochemistry and Microbiology, 52, 210 (2016)

9. L.C. VanLoon, E.A. VanStrien, Plant Defence: Biological Control, 55, 85 (1999)

10. V. V. Mosolov, T. A. Valuev, Biochemistry, 71, 838 (2006)

11. T. A. Revina, G. V. Kladnitskaya, N. G. Gerasimova, E. L. Gvozdeva, T. A. Valueva, Biochemistry, 75, 36 (2010)

12. A. Valencia-Jimenez, V. Arboleda, M. F. Grossidese, J. Agricult. Food chemistry, 56, 2315 (2008)

13. J. Gatehouse, Curr Protein Pept Sci, 12, 409 (2011)

14. L. E. Ivachenko, V. A. Kashin, E. S. Mascalzone, Methods for the study of polymorphism in soybean, 142 (2008)

15. E. V. Levites, Genetics of plant Isoenzymes, 145 (1986)

16. J.L. Wendel, N.F. Weeden, Izozymes in plant biology, 5 (1989)

17. L. E. Ivachenko, Enzymes as markers of soybean adaptation to growing conditions, $192(2011)$

18. H. Yang, R.M. Villani, H. Wang, M.J. Simpson, M.S. Roberts, M. Tang, X. Liang, Journal of Experimental and Clinical Cancer Research, 37(1), 1186 (2018)

19. J.A. Buege, S.D. Aust, Methods in Enzymology, 52, 302 (1978)

20. M.M. Posmyk, C. Bailly, K. Szafranska, J. Plant Physiol, 162(4), 403 (2005)

21. S.S. Sangaev, E.A. Trifonova, S.E. Titov, A.V. Romanova, I.S. Kolodyazhnaya, M.V. Sapotsky, V.I. Malinovsky, A.V. Kochetov, Genetics, 46, 131 (2010)

22. L. Jian-ke, Z. Yan-li, W. Yan-xia, W. Jian-hua, H. Qiu-hui, Agricultural Sciences in China, 8, 455 (2009)

23. N. Naoi, B. Teruniko, Arel and biochem, 4, 1835 (1977)

24. Q. Dong, K. Echigo, V. Raboy, Plant Physiology and Biochemistry, 149, 225 (2020)

25. H. Aoyamaa, D.M. Cavagisa, E.M. Tagab, C.V. Ferreiraa, Phytochemistry, 58, 221 (2001)

26. A.R. Akhatova, L.G. Yarullina, I.A. Shpirnaya, E.A. Zaikina, O.B. Surina, V.O. Tsvetkov, R.I. Ibragimov, Bulletin of Bashkir University, 17, 1278 (2012) 